
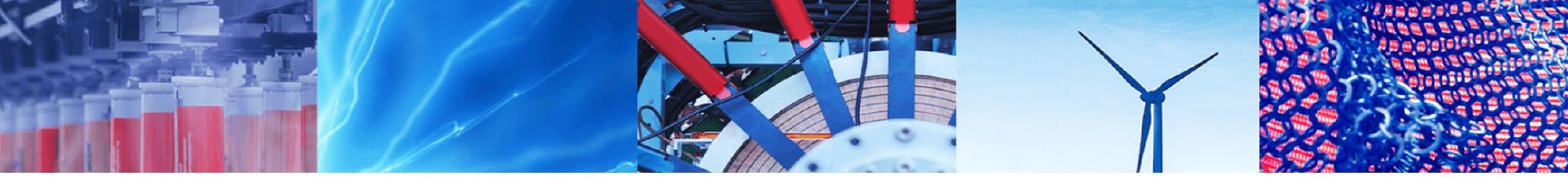

Research Article

\title{
Mathematical model of dissolved air flotation (DAF) based on impulse conservation law
}

\author{
Yurii Rybachuk $^{1}$ (D) Andrzej Jodłowski ${ }^{1}$
}

C The Author(s) 2019 OPEN

\begin{abstract}
Commissioning of new dissolved air flotation (DAF) installations and optimization of already existing installations takes at least one year of laboratory and pilot plant experiments. Such studies are labor-intensive. Using mathematical modeling, it is possible to minimize time and costs. For such purposes, mathematical model of the DAF process was developed based on the law of momentum (impulse) behavior and Navier-Stokes equations. The model allows to describe the kinetic relations between the water stream, air bubbles and aggregates arising as a result of coagulation of surface water pollution. The model takes into account the exchange of impulses between different phases as a result of laminar and turbulent flow. The developed model was used to prepare a simulation computer program. In order to check the feasibility of the model, laboratory tests were carried out under static conditions. Comparison of the results of laboratory tests with the results of computer simulation showed its suitability for analyzing the effectiveness of removing solid phase from water by means of dissolved air flotation. Proposed model was also compared with models proposed by different authors.
\end{abstract}

Keywords Surface water treatment · Dissolved air flotation computer modeling · Flocculation · Water air saturation

\section{Introduction}

Dissolved air flotation (DAF) is a method that enables the separation of the solid phase from the liquid phase by using the bubble growth phenomenon in the contact area of the two phases. In some situations, it is an alternative to other phase separation processes. The DAF process has strengths and weaknesses compared to conventional sedimentation. The advantages of DAF include compact design, short retention times, high hydraulic loads and small size of flocculation and flotation chambers, which leads to low capital costs [1, 2]. The short detention time allows for quick start-up, and the resulting high quality water ensures longer filtration cycles compared to sedimentation. DAF also provides a high degree of removal of parasitic protozoa, and due to the short time of water retention reduces the problems of taste and odor caused by phytoplankton decaying in sedimentation basins $[3,4]$.
DAF is relatively insensitive to water temperature. However, this process is not suitable for raw waters with high density suspensions. The disadvantages also include relatively complex plant systems and operating costs associated with the need to use recirculation stream of water.

It should also be noted that the separation mechanism used in DAF is relatively difficult to describe from a theoretical point of view. The separation mechanism is based on the interaction between aggregates (structures obtained as a result of coagulation of impurities) and air bubbles (appearing in the contact zone as a result of a sudden drop in the pressure of liquid saturated with air) [5-8]. This kind of interaction is very dynamic and also can be considered by computational fluid dynamics (CFD) [9-11]. It is true that there are mathematical models that describe the process of interaction and separation of such systems, but these models have their advantages and weaknesses. For example, classical DAF mathematical models

Yurii Rybachuk, jrybachuck@gmail.com | 'Department of Building, Architecture and Environment Engineering, Lodz University of Technology, 6 Politechniki Ave., 90924 Lodz, Poland.

SN Applied Sciences (2019) 1:541 | https://doi.org/10.1007/s42452-019-0560-y

Received: 28 January 2019 / Accepted: 3 May 2019 / Published online: 10 May 2019 
[5-8] considering mechanism of bubbles and aggregates interaction in detail, but have poor consideration of fluid dynamics and influence of reactor shape on the process, what is the main benefit of CFD.

The main objective of this article is to propose a mathematical model describing DAF system based on previous theoretical knowledge that allows process simulation. The developed mathematical relationships and algorithms were used to prepare a computer program that allows to perform DAF simulations and visualize its results in real time. To check the reliability of the proposed model, laboratory tests were carried out. The results obtained by means of computer simulation were compared with the results obtained in laboratory tests.

\section{Theoretical background}

The most important mathematical models allowing to describe phenomena occurring in the DAF process can be "single collector collision" (SCC) $[5,6]$ and "heterogeneous coagulation" $(\mathrm{HC})[7,8]$. The SCC model suggests that the interaction of bubbles and solid particles is based on the forces acting between air bubbles and aggregates and the adhesion of bubbles to the surface of the flocs. Such forms of interaction are based on the analysis of forces and cases of adhesion of one bubble to one aggregate. The extension of such analysis to the analysis of the process occurring in a given volume of liquid allows to describe the number of particles removed from the water as a result of flotation. This model can be used in the case when the bubble surface is large, the phenomenon of bubble capture on the surface of aggregates is very significant, and the flow regime of the multiphase system is laminar. The SCC model is more suitable for process descriptions in vertical flotation columns or in the case of a classic installation and its use to describe the processes taking place in the separation zone. In the case of turbulent flow, which is often observed in the contact zone, it is better to use the
$\mathrm{HC}$ model taking into account electric charges of aggregates and bubbles. The air bubbles have a negative electric charge, while the aggregates have a neutral electric charge, which results in their connection.

Although the use of these models allows to describe the effectiveness of DAF based on the values of selected parameters, the models are not perfect. For example, they do not take into account the possibility of flocs damaging through the effect of aggregates and bubbles collisions, which leads to a reduction in the likelihood of bubbles and flocs collisions. Also, the interactions between bubbles (the exchange of momentum between bubbles as a result of their collisions) and the influence of such phenomena on the system are not described. These models are also based on the adhesion of bubbles to the surfaces of flocks and their further formation in the reactor. This approach is not accurate enough. Not only the phenomenon of bubble and floc adhesion is observed, but also the phenomenon of bubble detachment from aggregates and the exchange of momentum between bubbles, which makes the process complex and dynamic.

Looking at the flotation system, it can be seen that the system consists of three phases, namely water, air and solid phase (aggregates, flocs). The mentioned phases actively interact with each other. An example of such interaction is acting of forces between flocs and air bubbles, collisions between bubbles, water resistance during rising of flocs and air bubbles. As a result of such interaction, pulse exchange between phases takes place.

To determine the exchange of pulses between phases, Navier-Stokes equations can be used. In the case of such a system, it is necessary to solve a set of Navier-Stokes equations for each phase (Table 1):

In Eqs. (1)-(7), Re is Reynolds number; $F_{\text {pop }}^{x}, F_{\text {res }}^{x} F_{\text {pop }}^{y}, F_{\text {res }}^{y}$-the pop and resistance forces by $x$ and $y$ axis; $V_{\text {sed' }}^{x}, V_{\text {sed }}^{y}$-velocity of aggregates sedimentation by $x$ and $y$ axis.

The force $F_{\text {wp }}$ and $F_{\text {op }}$ can be expressed according to Eqs. (8) and (9):
Table 1 System of NavierStokes equations for three phases important in DAF process

\begin{tabular}{lll}
\hline Phase & Equation & Eq. no. \\
\hline Water phase & $\frac{\partial U_{w}}{\partial t}+\frac{\partial U U_{w}}{\partial x}+\frac{\partial U V_{w}}{\partial y}=-\frac{\partial P}{\partial x}+\frac{\partial t}{R e} \Delta U_{w}$ \\
& $\frac{\partial V_{w}}{\partial t}+\frac{\partial U V_{w}}{\partial x}+\frac{\partial V_{w}}{\partial y}=-\frac{\partial P}{\partial y}+\frac{\partial t}{R e} \Delta V_{w}$ \\
Air phase & $\frac{\partial U_{b}}{\partial t}+\frac{\partial U U_{b}}{\partial x}+\frac{\partial U V_{b}}{\partial y}=-\frac{\partial P}{\partial x}+\frac{\partial t}{R e} \Delta U_{b}+F_{p o p}^{x}-F_{\text {res }}^{x}$ \\
& $\frac{\partial V_{b}}{\partial t}+\frac{\partial U V_{b}}{\partial x}+\frac{\partial V V_{b}}{\partial y}=-\frac{\partial P}{\partial y}+\frac{\partial t}{R e} \Delta V+F_{\text {pop }}^{y}-F_{\text {res }}^{y}$ \\
Solid phase & $\frac{\partial U_{p}}{\partial x}=V_{\text {sed }}^{x}+\frac{\partial U_{a}}{\partial x}\left(\right.$ if collision occurs, else $\left.\frac{\partial U_{a}}{\partial x}=0\right)$ \\
& $\frac{\partial V_{p}}{\partial y}=V_{\text {sed }}^{y}+\frac{\partial V_{a}}{\partial y}\left(\right.$ if collision occurs, else $\left.\frac{\partial U_{a}}{\partial y}=0\right)$ \\
Continuity equation & $\frac{1}{\delta} \frac{\partial P}{\partial t}+\frac{\partial U_{w}}{\partial x}+\frac{\partial V_{w}}{\partial y}=0$
\end{tabular}


$F_{\text {pop }}=V_{\mathrm{b}}\left(\rho_{l}-\rho_{\mathrm{g}}\right) g$

$F_{\text {res }}=\xi S \frac{V_{\text {rise }}^{2}}{2} \rho_{I}$

where $V_{\mathrm{b}}$ is the bubble volume, $\mathrm{m}^{3} ; \rho_{\mathrm{l}}$ and $\rho_{\mathrm{g}}$ are density of water and air, respectively, $\mathrm{kg} / \mathrm{m}^{3}, V_{\text {rise }}$ is the rise velocity of bubble, $\mathrm{m} / \mathrm{s} ; \mathrm{S}$ is the bubble contact surface, $\mathrm{m}^{2} ; \xi$ is the coefficient of environment resistance, which can be calculated according to Eq. (10) keeping count of Froud's number (Fr):

$\xi=\frac{8}{3} \frac{\left(1-\frac{\rho_{g}}{\rho_{l}}\right)}{\mathrm{Fr}}$

Thus, in the system of Navier-Stokes equations, the exchange of impulses between water and air is taken into account. In a simpler form, it is the speed of rising of aggregates at the next point of the generated mesh in the reactor space. The case of the effective interaction of bubbles with the aggregate is described by the probability of collision and randomization. In the case when the aggregates rising does not occur at the current point of the grid, the speed of aggregates movement at the current point is equal to the sedimentation rate:

$V_{\text {sed }}=\frac{d^{2}\left(\rho_{a}-\rho_{l}\right)}{18 \mu}$

where $\rho_{a}$ is the density of aggregate, $\mathrm{kg} / \mathrm{m}^{3} ; d$ is the aggregate's size, $\mathrm{m} ; \mu$ is the dynamical viscosity of environment, Pa s.

Velocity distribution for each phase can be obtained as the result of Navier-Stokes equations system solving for a given mesh and selected parameters of DAF. Knowing the value of the aggregates velocity of by $x$ and $y$ axis, it is possible to determine direction of the vector of phase total velocity:

$V_{a}=\sqrt{V_{a}^{x}+V_{a}^{y}}$

Sedimentation take place, when $V_{a}^{x}<0$ and $V_{a}^{y}<0$ or $V_{a}^{x}>0$ and $V_{a}^{y}<0$.

Knowing the number of grid points, where the direction of velocity is up, it is possible to calculate the efficiency of aggregates removal from water:

$\vartheta=\frac{N_{\text {cell }}^{\text {upvel }}}{N_{\text {cell }}}$ where $N_{\text {cell }}^{\text {upvel }}$ number of grid points where aggregate's velocity has positive value.

Another one process, which should be taken into consideration by the model, is checking the case of aggregates destruction, which depends on force of bubbles flow acting on aggregate. The strength of the bubble flow is equal to:

$F_{\text {bb }}=F_{\text {pop }}-F_{\text {res }}$

If $F_{\mathrm{bb}}>F_{\mathrm{a}}$, destruction of aggregate occurs and subsequently, the contact surface of the aggregate is decreasing. $F_{\mathrm{a}}$ is the strength of the aggregate, which can be determined with atomic microscope study or mathematical model allowing to determine such kind of parameter, $N$.

As mentioned previously, mechanism of treatment of DAF process is based on aggregates (flocs) rising using air bubbles. From this, it follows that the treatment process depends on two other processes (coagulation/flocculation and saturation). The results of these processes can be obtained using selected parameters. Thus, the efficiency of DAF treatment method depends on the geometrical parameters of floc aggregates and their strength, which can be determined using atomic force microscopy [12] or modeling with models allowing to simulate flocculation process and obtain such information [13].

The effectiveness of water treatment depends also on the size of the bubbles formed in the contact zone. The size of the bubbles depends in turn on the pressure used during saturation of water with air. It should also be noted that the number of bubbles is also very important in this case, because the number of bubbles influences the effectiveness of their interaction with flocs. The number of bubbles can be determined by the recirculation rate $R$, which determines the volume of saturated water that will be introduced into the reactor:

$R=\frac{100 Q_{\mathrm{s}}}{Q_{\text {in }}}$

where $Q_{\text {in }}$ is the discharge of water volume containing flocs, $\mathrm{m}^{3} / \mathrm{s} ; Q_{\mathrm{s}}$ is the discharge of saturated water volume, $\mathrm{m}^{3} / \mathrm{s}$.

As a rule, it is customary to use $R$ value in range of $5-20 \%$. Knowing flow rate of the water saturated with air in the chamber of DAF, it is possible to determine the number of bubbles generated in the chamber due to defined time step:

$N_{p}=\frac{V_{\mathrm{ds}}}{V_{\mathrm{b}}}$

where $V_{\mathrm{ds}}$ is the volume of dissolved air, $\mathrm{m}^{3} ; V_{\mathrm{b}}$ is the volume of one bubble, $\mathrm{m}^{3}$. 
Volume of air dissolved in water can be determined according to Henry`s law $[14,15]$. The diameter of bubbles depends on the pressure under which water is saturated with air and is determined by Eq. 17:

$R_{b}=\frac{2 \sigma}{P_{\mathrm{s}}-P_{\mathrm{n}}}$

where $\sigma$ is the surface tension of water, $\mathrm{kg} / \mathrm{s}^{2} ; P_{\mathrm{s}}$ is the pressure in saturator, $\mathrm{Pa} ; P_{\mathrm{n}}$ is the pressure in point of introduction of saturated air into reactor, $\mathrm{Pa}$.

Since the proposed method of simulation of the DAF process is mainly based on pulse exchange law, it is necessary to define a probability of collisions of flocs (aggregates) with air bubbles:

$P_{\text {col }}=1-\frac{S_{\mathrm{a}} N_{\mathrm{a}}}{S_{\mathrm{b}} N_{\mathrm{b}}}$

where $S_{a}$ is the contact surface of floc, $\mathrm{m}^{2} ; N_{\mathrm{a}}$ is the number of flocs per volume unit; $S_{b}$ is the contact surface of bubble, $\mathrm{m}^{2} ; N_{\mathrm{b}}$ is the number of bubbles per volume unit.

The values of $S_{a}$ and $N_{a}$ can be defined using microscopy analysis or mathematical model.

It is also necessary to note that it is better to determine the value of $P_{\text {col }}$ for selected volume of water and not for the entire volume of flocculation tank, since the concentration of these phases during treatment process can be changed.

\section{Materials and methods}

\subsection{Computer process simulation}

Thus, taking into account relationships described above, the algorithm of the model action has the following scheme, presented in Fig. 1 (model for static flotation reactor).

Algorithm shown in Fig. 1 contains two branches. The first one is the determination of size and strength of aggregates and volume of dissolved gas during saturation process. Determination of size and strength of aggregates was performed using mathematical modeling [13]. The second one is volume of air dissolved which can be defined by Henry's law. These parameters are necessary for the collision probability between aggregates and air bubbles determination. Strength of aggregates is necessary for destruction cases definition. One more important step, which is next in this algorithm, is the shape grid definition. Grid was used for solving Navier-Strokes equations, what allowed to obtain velocity distribution. Also should be noted that the algorithm showed in Fig. 1 has cycle character and stops after percent of recirculation reached, due to static character of laboratory installation, which was used for proving mathematical model feasibility.

Proposed mathematical relationships and algorithms were translated into a computer program. $\mathrm{C}++$ programming language and framework Qt were used to write the program. OpenGL library was used to visualize the results of simulation. All the simulations were performed using Intel Core i7-4650U 1.7-2.3 GHz CPU (2 cores, 4 threads) and graphical card NVIDIA GeForce $840 \mathrm{M}$. Multithreading technology was not used to write this part of program.

\subsection{Laboratory experiments}

Laboratory studies were carried out to check the feasibility of proposed method. Tap water contaminated with humic acids extract at the dose of $13.6 \mathrm{ml} / \mathrm{L}$ was used as studied water. The color of obtained water was $69.0 \pm 0.1 \mathrm{mg} \mathrm{Pt} / \mathrm{L}$, turbidity was $12.0 \pm 0.1 \mathrm{NTU}$, and $\mathrm{pH}$ of water was $7.0 \pm 0.1$. Coagulation/flocculation was performed with aluminum sulfate $\left(\mathrm{Al}_{2}\left(\mathrm{SO}_{4}\right)_{3} \cdot 18 \mathrm{H}_{2} \mathrm{O}(10 \%)\right.$.

The setup of installation used is shown in Fig. 2. Transparent plastic pipe was used as a reactor for DAF. The height of the reactor was of $2 \mathrm{~m}$, and its diameter was of $0.08 \mathrm{~m}$. Stainless-steel pressure container was used as saturator reservoir. The diameter of saturator was of $0.19 \mathrm{~m}$, and its height was of $0.35 \mathrm{~m}$. (The available pressure was of $0.6 \mathrm{MPa}$.) The water saturation was performed using AMICO 50/2500SF compressor (effective performance $0.115 \mathrm{~m}^{3} / \mathrm{min}$, maximal pressure-0.8 $\mathrm{MPa}$ ). Laboratory experiments were conducted at the room temperature.

The process of mixing was performed using handmade stainless-steel stirrer. The rotation of stirrer was realized using electric engine placed on the top of whole construction. After coagulation/flocculation performance and water saturation process (saturation pressure could be applied in range of $0.45-0.60 \mathrm{MPa}$ ), flotation was performed using the percent of recirculation $(R)$ in range of 5-20\% from polluted water volume.

As an example of laboratory studies was chosen run of laboratory simulation, which had operated parameters such as dose of $\mathrm{Al}_{2}\left(\mathrm{SO}_{4}\right)_{3} \cdot 18 \mathrm{H}_{2} \mathrm{O} 10 \%-50 \mathrm{mg} \mathrm{Al} / \mathrm{L}$; stirrer's velocity $50 \mathrm{rpm}$; flocculation time- $8 \mathrm{~min}$; pressure of water saturation- $0.55 \mathrm{MPa}$ and percentage of recirculation $(R)-15 \%$.

Water purified by flotation method was analyzed using spectrophotometer Hitachi U-2001 (to determine water color) and turbidity meter Hach $2100 \mathrm{~N}$ IS (to determine water turbidity). 
Fig. 1 Algorithm of DAF simulation (static flotation reactor)

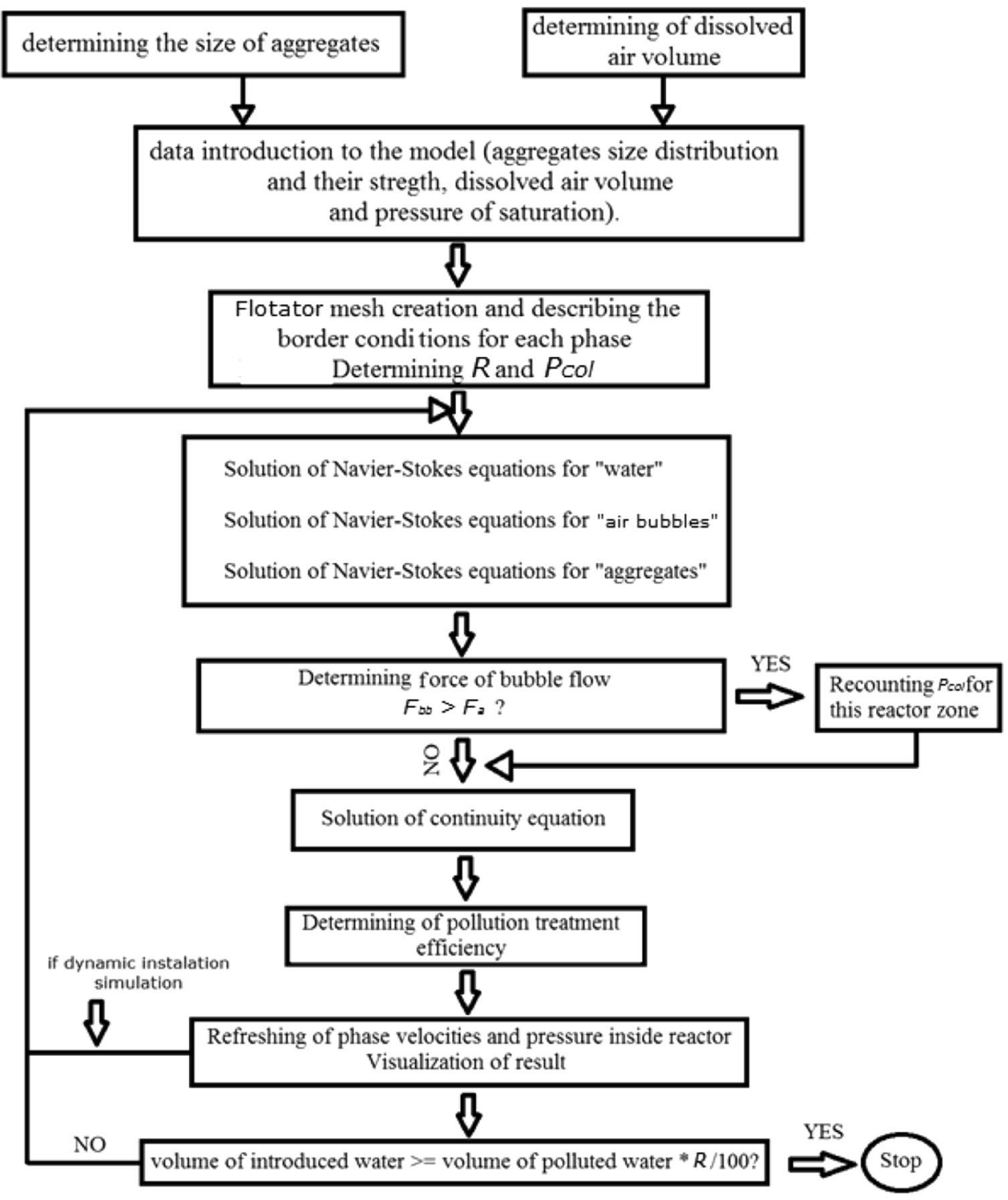

\section{Results and discussion}

Results of all laboratory studies runs, which are shown in Table 2, were obtained using optimal values of inspected parameters from previous runs.

Optimal dose of coagulant was studied using $5 \mathrm{~min}$. flocculation time and $40 \mathrm{rpm}$ of mixing velocity. Optimal coagulant dose was determined as $50 \mathrm{mg} \mathrm{Al} / \mathrm{L}$, so the next operative parameter in Table 2 (optimal mixing velocity) was determined using $50 \mathrm{mg}$ of $\mathrm{Al} / \mathrm{L}$ coagulant dose and so on. Table 2 contains all important DAF operative parameters. It also proves flexibility of proposed mathematical model. The result of such applied parameters was purified water, which had the rate of color decrease of $85.96 \%$ and decrease in turbidity of $68.08 \%$.

Optimal operation parameters obtained during laboratory studies were used for process computer simulation.
Model with such modification can be used to analyze laminar and turbulent zones in reaction tank. The results of this computer simulation are shown in Fig. 3.

The proposed model allowed also to analyze aggregates destruction during their interaction with air bubbles. Anyway, it was observed during computer simulation of the process that such phenomena of destruction do not occur in the reactor. Also, such kind of aggregates destruction was not observed during laboratory studies.

Moreover, it should be noted that written program allows to visualize obtained results of simulation in real time. Such option allows to follow how does treatment efficiency changes during flotation process (Fig. 3).

Treatment efficiency was very limited at the start of simulation (first appearance of dissolved gas in reactor), due to the biggest part of discretization grid, which had sedimentation value of velocity. Efficiency increased up 


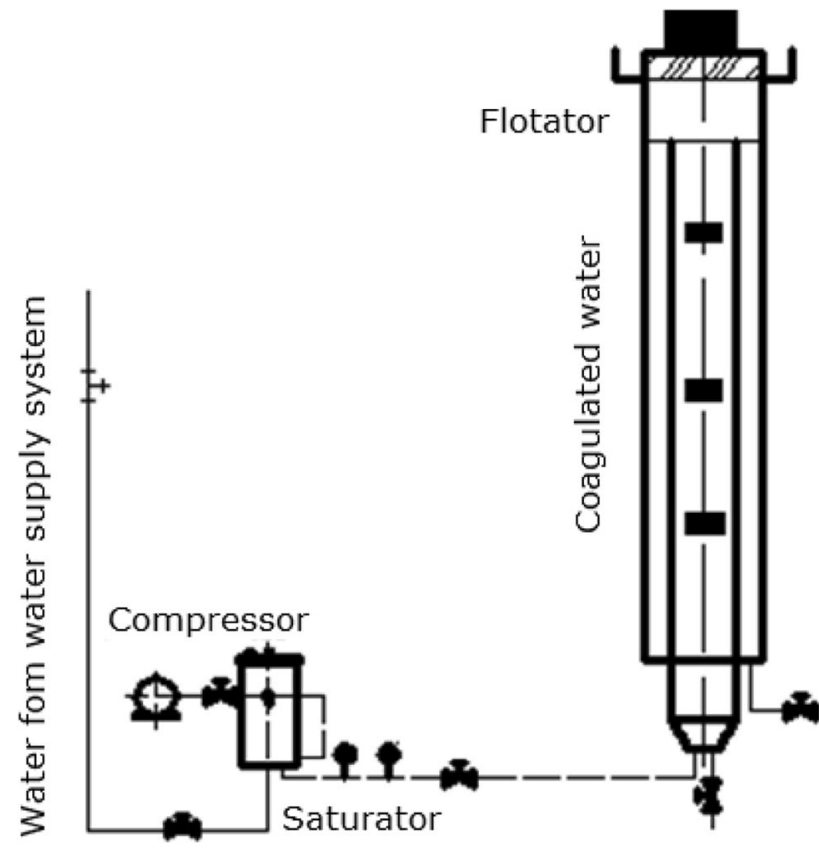

Fig. 2 Setup of the laboratory stand (static DAF installation)

to $80-88 \%$ during the treatment (relatively stable value of treatment efficiency). After this stabilization of phases appeared in reactor, treatment efficiency was in the range of $77-87 \%$. Such phenomena demonstrated dynamics and deviation of purification efficiency obtained using defined operative parameters, what can be often observed in real conditions. Such dynamics of purification efficiency can be explained by turbulence conditions inside reactor. (As the result, some areas of reactor had vorticity effects, which were undesirable.) Equation 13 takes into consideration such undesired vorticity phenomena. Proposed model includes also analysis of aggregates destruction cases during their interaction with air bubbles, but how was observed during computer simulation of the process, such phenomena of destruction did not occurred in reactor (due to low value of bubbles mass). Also, such kind of aggregates destruction was not observed during laboratory studies.

Finally, proposed model was compared with "single collector collision" (SCC) model $[5,6]$ and "heterogeneous coagulation" (HC) model $[7,8]$. Since installation used to verify proposed model had static character, it has combined contact and separation zones. Regarding this comparison of mentioned and proposed models, analyzing of contact zone was performed. Authors of $[5,6]$ represented contact zone efficiency under different values of floc variables (such as size and density) and physical parameters (such as environmental temperature and air bubbles composition as the result of different water air saturation pressure). The value of contact zone efficiency for $10 \mu \mathrm{m}$ floc
Table 2 Influence of different operative parameters on water color removal by DAF (\%)

\begin{tabular}{|c|c|c|}
\hline Process parameter applied value & $\begin{array}{l}\text { Labora- } \\
\text { tory } \\
\text { studies }\end{array}$ & $\begin{array}{l}\text { Computer } \\
\text { simulation }\end{array}$ \\
\hline \multicolumn{3}{|l|}{ Coagulant dosage, $\mathrm{mg} \mathrm{Al} / \mathrm{L}$} \\
\hline 20 & 87.1 & 84.1 \\
\hline 30 & 87.5 & 86.2 \\
\hline 40 & 90.8 & 87.1 \\
\hline 50 & 90.9 & 87.8 \\
\hline 60 & 89.0 & 80.5 \\
\hline \multicolumn{3}{|c|}{ Mixing intensity during flocculation, rpm } \\
\hline 20 & 90.8 & 85.0 \\
\hline 30 & 89.5 & 85.9 \\
\hline 40 & 89.0 & 87.1 \\
\hline 50 & 89.9 & 86.3 \\
\hline 60 & 88.6 & 86.4 \\
\hline \multicolumn{3}{|l|}{ Flocculation time, $\min$} \\
\hline 5 & 89.9 & 87.8 \\
\hline 8 & 90.3 & 86.4 \\
\hline 10 & 90.9 & 85.0 \\
\hline 12 & 87.7 & 85.2 \\
\hline 14 & 86.1 & 84.3 \\
\hline \multicolumn{3}{|l|}{ Recirculation, \% } \\
\hline 5 & 36.5 & 44.4 \\
\hline 10 & 70.0 & 70.1 \\
\hline 15 & 85.9 & 82.9 \\
\hline 20 & 91.1 & 87.7 \\
\hline \multicolumn{3}{|l|}{ Saturation pressure, $\mathrm{MPa}$} \\
\hline 0.45 & 87.7 & 83.1 \\
\hline 0.50 & 90.3 & 85.2 \\
\hline 0.55 & 91.1 & 87.5 \\
\hline 0.60 & 90.2 & 87.1 \\
\hline
\end{tabular}

size was in range of $80-85 \%$ and increased to $95 \%$ with increase in floc size to $100 \mu \mathrm{m}$, respectively. The average size of flocs considered in our laboratory studies and computer simulations was in range of 30-40 $\mu \mathrm{m}$. Regarding the results shown in Table 2, the average purification efficiency was in the range of $80-87 \%$. In HC model, results of modeling are represented by removal efficiency under different values of recirculation percent. Our results of computer simulations and laboratory studies were compared with the results represented by $\mathrm{HC}$ model $[7,8]$, only until $8 \mathrm{~s}$ of simulation (because of static character of installation considered in laboratory studies and computer simulations). On the first second of simulation under similar percent of recirculation, removal efficiency in $\mathrm{HC}$ model was in range of $18 \%$ and in our model (Fig. 3) $-16.6 \%$. On fourth and later seconds, removal efficiency in $\mathrm{HC}$ model reached its maximum, which is in range $80-90 \%$. In proposed model, purification efficiency on fourth and later seconds was 

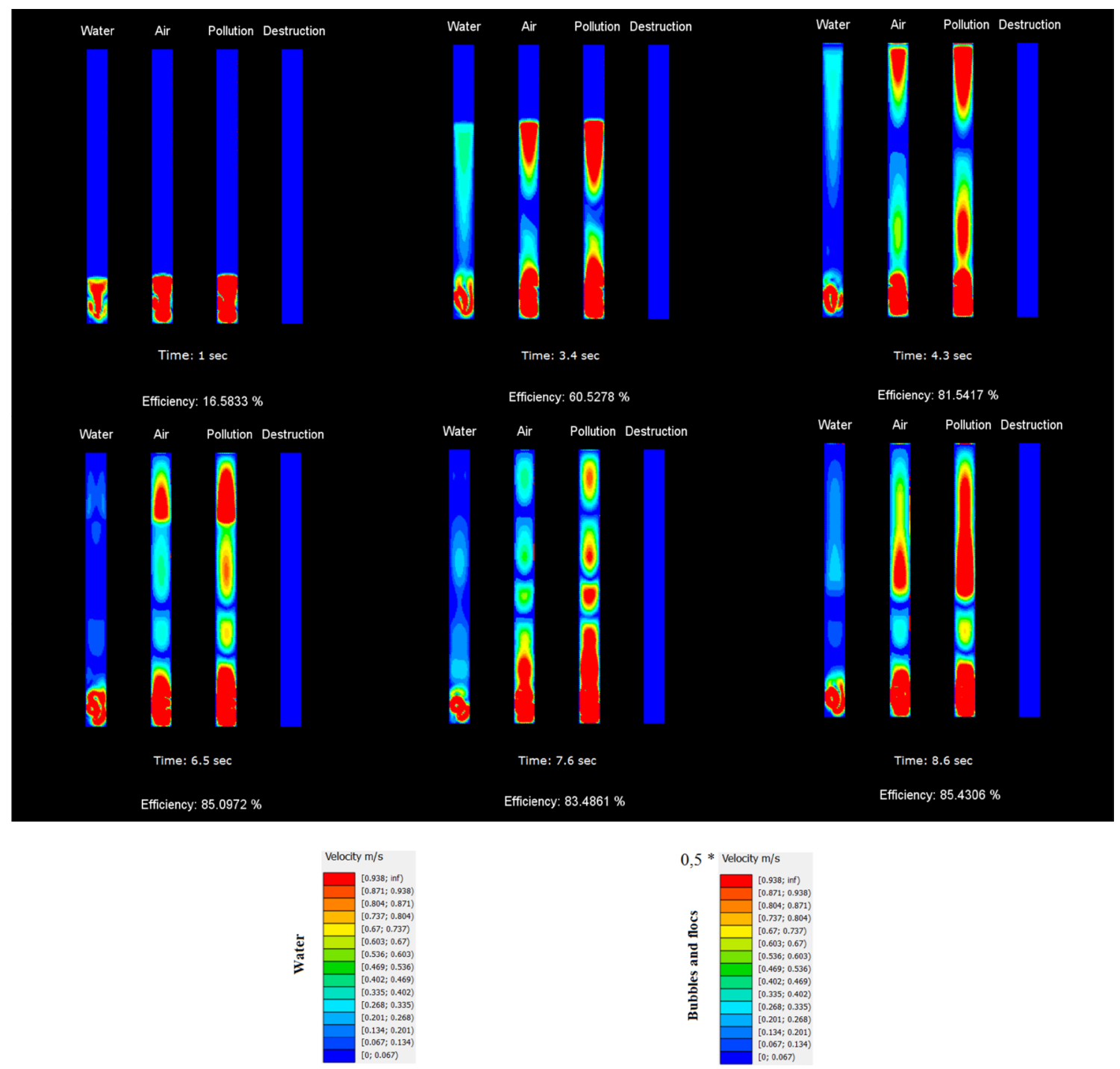

Fig. 3 The velocity distribution of phases and treatment efficiency (static DAF installation)

oscillating in range of $81-86 \%$. As can be seen, deviation between results represented by different models is not very high, but it exists. As mentioned before in Eq. 13, correcting purification efficiency considering movement direction of solid phase is given by CFD modeling. Regarding this not all of cases of bubbles and aggregates interaction lead to eliminating impurities from water.

\section{Conclusions}

The paper presents a proposal for a model of coagulation/flocculation/dissolved air flotation process in which the law of conservation of momentum during collisions between aggregates resulting from coagulation/ flocculation and air bubbles, as well as between air bubbles, was used. The Navier-Stokes equations which are the foundation of CFD were used in the interpretation of the phenomenon. The model includes the reactor geometry and hydrodynamic conditions prevailing in the model as well as the main parameters of the coagulation/flocculation and saturation processes.

The proposed model showed satisfactorily accurate results of simulation regarding the effectiveness of water treatment containing humic substances. The difference between the results of the research on the effectiveness of the removal of substances causing the color of water carried out on a laboratory scale and the results of simulations at different doses of aluminum sulfate were in the range of 1.29-6.72\%. Small differences were also found by examining the influence of the rotational speed of the impeller 
during the flocculation phase (4.42\% on average). In the case of tests regarding flocculation time, it was found that the difference between the results of computer simulation and the results of laboratory tests was in the range of $2.13-4.97 \%$. These differences were also small in the case of analysis of the parameters of the dissolved air flotation process. By analyzing the impact of the recirculation rate on the effectiveness of water purification expressed by the degree of color removal, differences between simulation results and laboratory results were found at $2.88 \%$ on average, and when the effect of saturation pressure on the color removal efficiency was evaluated, the difference was $3.28 \%$ on average.

The obtained high degree of compliance of the coagulation/flocculation phase modeling and flotation proves that the proposed mathematical model can be used during the simulation of the effectiveness of water treatment by the DAF method.

\section{Compliance with ethical standards}

Conflict of interests The authors declare that they have no conflict of interest.

Open Access This article is distributed under the terms of the Creative Commons Attribution 4.0 International License (http://creativeco mmons.org/licenses/by/4.0/), which permits unrestricted use, distribution, and reproduction in any medium, provided you give appropriate credit to the original author(s) and the source, provide a link to the Creative Commons license, and indicate if changes were made.

\section{References}

1. Crossley IA, Valade MT (2006) A review of the technological developments of dissolved air flotation. Wat Sup Technol AQUA 55(7-8):479-491

2. Haarhoff J (2008) Dissolved air flotation: progress and prospects for drinking water treatment. Wat Sup Technol AQUA 57(8):555-567
3. French K, Guest RK, Fich GR, Haas CN (2000) Correlating cryptosporidium removal using dissolved air flotation in water treatment. Wat Res No 16:4116-4119

4. Sun F, Pei HY, Hu WR, Li XQ, Ma CX, Pei RT (2013) The cell damage of Microcystis aeruginosa in PACl coagulation and floc storage process. Sep Purif Technol 115:123-128

5. Edzwald JK (1995) Principles and applications of dissolved air flotation. Wat Sci Technol 31(3-4):1-23

6. Haarhoff J, Edzwald JK (2004) Dissolved air flotation modelling: insights and shortcomings. Wat Sup Technol AQUA 53(3):127-150

7. Fukushi K, Tambo N, Matsui Y (1995) A kinetic model for dissolved air flotation in water and wastewater treatment. Wat Sci Technol 31(3-4):37-47

8. Matsui Y, Fukushi K, Tambo N (1998) Modeling, simulation and operational parameters of dissolved air flotation. Wat Sup Technol AQUA 47(1):9-20

9. Ta CT, Beckley J, Eades A (2001) A multiphase CFD model of DAF process. Wat. Sci. Tech. 43(8):153-157

10. Hague J, Ta CT, Biggs MJ, Sattary JA (2001) Small scale model for CFD validation in DAF application. Wat Sci Technol 43(8):167-171

11. Bondelind $M$, Sasic $S$, Kostoglou M, Bergdahl L, Pettersson $T$ (2010) Single-and two-phase numerical models of dissolved air flotation: comparison of 2D and 3D simulations. Colloids and surfaces a: physicochem. Eng Aspects 365:137-144

12. Leito FL, Bueno CC, Da Róz AL, Ziemath EC, Oliviera ON Jr (2012) Theoretical models for surface forces and adhesion and their measurement using atomic force microscopy. Int J Mol Sci 13:12773-12856

13. Rybachuk Y, Jodłowski A (2018) Computer simulation of the aggregates formation during flocculation process. In: E3S Web of conferences, vol 44. https://doi.org/10.1051/e3sconf/20184 400154

14. Haarhoff J, Steinbach S (1996) A model for the prediction of the air composition in pressure saturators. Wat Res 30(5):3074-3082

15. Haarhoff J, Steinbach S (1997) A comprehensive method for measuring the air transfer efficiency of pressure saturators. Wat Res 31(12):981-990

Publisher's Note Springer Nature remains neutral with regard to jurisdictional claims in published maps and institutional affiliations. 